\title{
DOCUMENTARIO
}

\section{Uma experiência fluminense de administração planificada}

(Recuperação e Desenvolvimento do Municipio de Rio Bonito)

\section{Celso Peçanha}

Inúmeros trabalhos dignos de rigorosa análise e meditação, no tocante aos problemas fundamentais dos Municipios, têm sido divulgados, a intervalos regulares, pelo Serviço de Documentação do D. A. S. P. destacando-se, no conjunto das publicaçōes aparecidas, os volumes da Série D.A.S.P.-Instituto Brasileiro de Ciências Administrativas. Da mesma forma, a Revista do Serviço Público, através de uma Seção inteiramente dedicada aos assuntos de Govêrno e Administração Municipal, vem proporcionando, inintertuptamente, aos Prefeitos. Vereadores, Autoridades e estudiosos, em geral, o conhecimento dos trabalhos e contribuiçôes técnicas mais importantes no que se refere aos mencionados problemas. Esse notável empreendimento cultural traduz um esfôtço patriótico de assistência técnica às Prefeituras e Câmaras, contribuindo para proporcionar ao Municipalismo uma densa substância de objetividade, orientando -o no sentido da emancipação global e do desenvolvimento planificado das Comunas. $O$ que tem sido essa incessante atividade de repercussão nacional pode ser atestado pelos seus resultados e pelos depoimentos autorizados dos próprios Municipios os quais se habituaram a ver no Serviço de Documentação do D.A.S.P. um poderoso fator de estimulo à implantação de novas técnicas e métodos de Administração no roteiro da modernização, do planejamento econômico-social, da descentralização, da racionalização dos investimentos, da seleção e formação dos funcionários locais, - em suma, a benemérita Campanha consubstanciada nas metas e projetos do Sistema Geral da Operação Municipio. O fato é que as Prefeituras e Câmaras de Vereadores de todo o Brasil, as Assembléias Legislativas dos Estados, a Câmara dos Deputados e o Senado da República, os Jornais e Radioemissoras mais importantes, as principais Autoridades Federais e Estaduais, o Alto Clero, os Oficiais Superiores das Fôrças Armadas, 
entre outros, conhecem e acompanham as iniciativas e trabalhos do Serviço de Documentação $d$ oD.A.S.P. e da Revista do Serviço Público no que diz respeito à emancipação global e ao desenvolvimento planificado dos Municipios - verdadeira mobilização contra o subdesenvolvimento e o pauperismo. Deve ser acentuado, ainda, o aspecto altamente educativo dos aludidos estudos, projetos e contribuições técnicas selecionados pela Revista do Serviço Público. E' de se notar, além disso, a surpreendente regularidade observada na distribuição dêsses trabalhos, dentre os quais un dos mais importantes é o divulgado na presente edição: "Ulma Experiência Fluminense de Administração Planificada" (Recuperação e Desenvolvimento do Municipio de Rio Bonito), objeto do Projeto $n^{\circ} 3.581-57$ apresentado na Câmara Federal pelo então Deputado Celso Peçanha, atual Vice-Governador do Estado do Rio, a 4 de dezembro de 1957. Dispõe o Projeto 3.581 sôbre a realização da Operação Rio Bonito (Desenvolvimento Planificado do Municipio: I - Obras, Empreendimentos e Serviços de Desenvolvimento Econômico-Social; II - Plano Diretor da Cidade de Rio Bonito: III - Reorganização Administrativa; IV - Atos Complementares). Nos têrmos dêsse importante projeto, fica o Poder Executivo autorizado a abrir, pelo Ministério da Viação e Obras Públicas, o crédito especial de Cr\$ 15.000.000,00 (quinze milhões de cruzeiros) como contribuição do Govêrno Federal à execução da Operação Rio Bonito. "Uma Experiência Fluminense de Administração Planificada" traça para Rio Bonito - próspera Comuna do Estado do Rio - um modêlo digno de ser imitado pelos demais Municipios, a exemplo de Cabo Frio, Barra do Pirai, Nilópolis, Duque de Caxias, que se preparam para realizar experiências idênticas de administração planificada. O ilustre autor da Operação Rio Bonito, Vice-Governador CELso PeÇAnHa é, reconhecidamente, uma das maiores autoridades no campo da Administração Municipal pelo fato de ter sido quatro vêzes Prefeito, no Estado do Rio (Rio Bonito e Bom Iardim) e duas vêzes Deputado Federal. Naturalmente a Prefeitura de Rio Bonito aguarda, com justificada ansiedade, que o Grupo Parlamentar Municipalista promova, na Câmara e no Senado, o andamento acelerado do Projeto $n^{\circ} 3.581-57$, a fim de que possa realizar, com pleno exxito, a Operação Rio Bonito - ponto de partida para o desenvolvimento planificado do Municipio. Oportunamente, a Revista do Serviço Público proporcionará aos seus leitores novos estudos e informações relativos às tendências, problemas e perspectivas no Estado do Rio e no Brasil. - (Nota da Redação). 
PROJETO N. $.^{\circ} 3.581-1957$

Autoriza o Poder Executivo a abrir, pelo Ministério da Viação e Obras Públicas, o crédito especial de Cr $\$ 15.000 .000,00$ como contribuição do Govêrno Federal à ‘ realização ida Operação Rio Bonito (Desenvolvimento Planificado (do Municipio : I $\downarrow$ Obras, Em preendimentos e Serviços do Desenvolvimento Econômico e Social; II - Plano Diretor da Cidade; III $\vdash$ Reorganização Administrativas IV - Atos Complementares).

\section{(Do Sr. Celso Peçanha)}

Art. 1. $0^{\circ}$ O Poder Executivo fica autorizado a abrir o crédito especial de Cr\$ 15.000.000,00 (quinze milhões de cruzeiros), pelo Ministério da Viação e Obras Públicas, para, em colaboração com o Govêrno do Estado do Rio de Janeiro, participar do esquema de financiamento misto da Operação Rio Bonito (Desenvolvimento Econômico e Social do Município).

Art. $2 .^{\circ} \mathrm{O}$ crédito de que trata esta Lei será automàticamente registrado no Tribunal de Contas, distribuído ao Tesouro Nacional e pôsto à disposição da Prefeitura Municipal de Rio Bonito em conta especial vinculadá à execuçâo dos Projetos integrantes da Operação Rio Bonito (Desenvolvimento Planificado do Municipio).

$\S 10^{\circ}$ A aplicação do referido crédito será efetuada progressivamente nas obras, empreendimentos e serviços prioritários que forem objeto de acôrdos ou convênios firmados entre a Prefeitura e os Ministérios ou quaisquer órgãos do Govêrno Federal, devendo a beneficiária prestar contas das quantias aplicadas na forma da Lei.

$\S 2^{\circ}$ A Prefeitura Municipal de Rio Bonito divulgará relatório trimestral do andamento dos trabalhos realizados independentemente das inspeções locais que venham a ser efetuadas pelo Ministério da Viação e Obras Públicas e pelo Govêrno do Estado do Rio de Janeiro.

Art. 3. ${ }^{\circ}$ O Ministério da Viação e Obras Públicas mediante Convênio Especial com o Govêrno do Estado do Rio de Janeiro e a Prefeitura Municipal de Rio Bonito acompanhará a execução das Obras, Empreendimentos e demais Projetos integrantes da Operação Rio Bonito e notadamente o Plano Diretor da Cidade - participando do planejamento e fiscalizando o andamento dos respectivos trabalhos.

Parágrafo único. O Ministro de Estado da Viação e Obras Públicas, dentro de 30 dias, designará um Engenheiro especializado $\mathrm{em}$ assuntos de planejamento econômico ou urbanismo, para, nos têrmos do Convênio Especial referido no art. $3 .^{\circ}$ representar o Govêrno Federal e colaborar na eficiente execução da Operação Rio Bonito e plena observância de suas metas e prazos.

Art. 4. Esta lei entrará em vigor na data de sua publicação, revogadas as disposições em contrário.

Rio de Janeiro, em 4 de dezembro de 1957. - Celso Peçanha. 


\section{JUSTIFICAÇÃo}

O Projeto de Lei anexo que tenho a honra de submeter à alta deliberação do Congresso Nacional dispõe sôbre a participação do Govêrno Federal no esquema de financiamento misto da Operação Rio Bonito (Desenvolvimento Planificado do Município: I - Obras, Empreendimentos e Serviços de Desenvolvimento Econômico e Social; II - Plano Diretor da Cidade; III - Reorganização Administrativa; IV - Atos Complementares).

2. A contribuição do Govêrno Federal, nos têrmos do referido Projeto, antecipará o estabelecimento de um sistema novo e revolucionário de colaboraçãc e assistência técnico-financeira entre a União e o Município de Rio Bonito, em regime de integral cooperação com o Govêrno estadual. A simples leitura da documentação anexa dispensa uma justificação mais longa e exaustiva das razões de ser os motivos determinantes da necessária e urgente aprovação dêsse Projeto que marca, efetivamente o início de uma política prática, eficiente e inteiramente original no âmbito da cooperação interadministrativa, destinada a fortalecer as Unidades básicas da Federação brasileira - os nossos olvidados e desservidos Municipios.

3. Dispenso-me, portanto, de alongar-me na justificação do Projeto que tenho a satisfação de apresentar. Satisfação tanto maior quanto reconheço, com a minha experiência de Prefeito na velha, nobre e laboriosa província fluminense, - quatro vêzes prefeito municipal - que não é possivel emancipar e desenvolver os Municípios brasileiros sem uma renovação urgente e completa dos métodos de govêrno e administração. Essa experiência pessoal e direta, o conhecimento objetivo e prático dos problemas municipais, - como ex-prefeito em diversas oportunidades - são, entre outros, os motivos que me levam a propor a aprovação do Projeto de Lei anexo.

4.. A Operação Rio Bonito - uma das Projeções Locais da Operação Municipio de âmbito nacional - foi discutida e aprovada pelo IV Congresso Nacional de Municipios realizado de 27 de abril a 5 de maio do corrente, no Rio de Janeiro, sendo objeto de uma Recomendaçã́o Especial dos Prefeitos e Vereadores do Brasil reunidos nesse Conclave pleiteando sua aprovação imediata como modêlo digno de ser adotado pelas Prefeituras e Câmaras Municipais de todo o Brasil. Ela pretende, em resumo, planificar, ampliar e desenvolver a capacidade financeira, econômica, administrativa, demográfica e social do Municipio; aplicar, da melhor maneira possível, suas disponibilidades financeiras, orçamentárias e extra-orçamentárias - daí o planejamento sensato e criterioso tendo em vista o aproveitamento científico dos recursos naturais de Rio Bonito. Em função do potencial geodemográfico, socio-cultural, técnico e econômico do Município, será, então, realizada a Oppração Rio Bonito - mediante acôrdos ou convênios multilaterais participando dos empreendimentos programados a União, o Estado do Rio e o Município. Estamos, por conseguinte, em face de um Municipalismo de novo estilo: - dai a grande repercussão da Operação Rio Bonito que foí inclusive, traduzida para o francês pelo Prof. Alexis Maurin e levada aos debates do recente Congresso de Madri como expressão de uma fórmula singular e sumamente objetiva da moderna administração municipal. 
5. Aproveito a oportunidade para congratular-me com Sua Excelência - Embaixador da França, Sr. Bernard Hardion com Mme. Gabrielle Mineur, chefe dos Serviços Culturais da Embaixada da França e, sobretudo, com o Prof. Alexis Maurin, pelo grande serviço prestado a Rio Bonito, ao Estado do Rio e ao Brasil, traduzindo para o belo idioma gaulês, o texto da Operação Rio Bonito. Essa tradução tornou possivel a divulgação que se está fazendo, no momento em francês, inglês e espanhol, do notável projeto que resume as verdadeiras tendências e perspectivas do Municipalismo brasileiro.

6. Rio Bonito tem 111 anos de existência. Os 450 quilômetros quadrados do Município foram outrora, na época do desbravamento ocupados pelos Tamoios. Seu território integrava a Capitania de São Vicente. A partir de 1755 começaram as primeiras incursões civilizadoras com os trabalhos de colonização da terra. Datas significativas na história de Rio Bonito são as seguintes: 27 de agôsto de 1786 recebe a localidade predicamento de freguesia; 7 de maio de 1846, elevação à categoria de Vila, com desmembramento de seu território de Saquarema e o atual Silva Jardim. Estava criado - Município e o 7 de maio é a data magna da Comuna. A 16 de janeiro de 1890 Rio Bonito recebeu a categoria de cidade. Quem vai hoje à cidade estranha seu título. Afinal de contas não existe um rio, e sim um córrego a se extinguir. Mas isso é o que se vê agora. Outrora correra por ali majestoso rio, emcujo percurso, desde a nascente apresentava uma empolgante variedade de deslumbrantes aspectos. A Igreja Matriz de Rio Bonito é um notável monumento histórico e artístico. A data do final de sua construção roincide com a data da elevação do lugarejo à condição de Vila, isto é, a 7 de maio de 1846. Chama-se Igreja de Nossa Senhora da Conceição. Está. hoje, denominada Praça Portela.

O Município conta com interessantes monumentos artísticos e históricos. além da Matriz. Entre outros, podem ser enumerados os seguintes: Herma de Manuel Duarte, Obelisco e Marco Centenário, na Praça Fonseca Portela; Igreja de Nossa Senhora de Santana, no $10^{\circ}$ Distrito; Igreja de Nossa Senhora da Conceição de Braçanã, em Braçanã; Capela de Nossa Senhora de Boa Esperança em Boa Esperança. A construção de todos êsses templos católicos tem data bastante remota.

Permitam-me, agora, os Senhores Deputados, algumas informações no que se refere à educação e cultura em Rio Bonito. Existem 45 estabelecimentos de ensino primário, dois de ensino ginasial, um de ensino normal e um de ensino técnico comercial. Funciona na cidade o "Ginásio Manuel Duarte" da Campanha Nacional de Educandários Gratuitos, que vem prestando inestimáveis serviços à juventude rio-bonitense. O Ginásio de Rio Bonito, em que são mantidos cursos ginasial, normal e técnico de comércio, é particular. Quanto às atrações turísticas Rio Bonito é um Município privilegiado. O aproveitamento de pontos pitorescos em atrações turísticas poderia incrementar uma rendosa indústria de turismo, pelo seu aproveitamento industrial, tal como preconizado na Operação Rio Bonito.

Cada visitante é um comprador, em potencial, não só de "recuerdos" de muitos artigos e inclusive, pode propiciar o desenvolvimento de diversas atividades, como a de hotéis, restaurantes e transportes. Aliás, a maioria dos 
Municípios brasileiros possui pontos pitorescos a apresentar aos forasteiros. U território brasileiro é pródigo em paisagens agradáveis. $\mathrm{O}$ que acontece é que nấc se dá, no mais das vêzes, o devido valor ao assunto e, assim, uma fonte de rendas deixa de carrear substanciais recursos financeiros ao erário das municipalidades.

Quanto aos transportes, Rio Bonito está ligado à Capital da República pela Estrada de Ferro Leopoldina que também a liga à Capital do Estado do Rio, Niterói. Fazendo transporte de passageiros entre Niterói e Rio Bonito há duas emprêsas de ônibus e micro-ônibus, com um grande movimento diário.

No setor econômico, a bananicultura é o alicerce econômico de Rio Bonito. Constituindo a atividade agrícola de maior expressão em Rio Bonito, a bananicultura graças à rusticidade da própria planta, tem alcançado algum desenvolvimento, o qual, uma vez posta em execução, a Operação Rio Bonito será multiplicado. Na Serra do Sembê localizam-se as maiores plantações. A produção estimada é de 4 milhões e 500 mil cachos anuais, destinando-se grande parte à exportação para o Distrito Federal. Aliás, o caminhão carregado de bananas é quase um tipo característico na cidade e na estrada; não menos característico é o homem que nêle trabalha. Tomando-se em conta que cada cacho pesa, em média, 15 quilos, pode a produção anual ser avaliada em cêrca de 66 milhões de cruzeiros, cifra vultosa, sem dúvida. Porém, não há uma racionalização na produção, industrialização e distribuição da banana, fato êsse que prejudica, de certo modo, o desenvolvimento da cultura. A reunião dos produtores em tôrno do objetivo de oferecer ao mercado consumidor bananas de melhor qualidade a preço mais reduzido viria a proporcionar um progresso extraordinário para o Municipio. Com a Operação Rio Bonito o Município, dentro de 5 anos produzirá, industrializará e exportará uma produção global de bananas superior à do litoral paulista e do resto do Brasil inclusive.

7. Estes, em traços gerais, é o retrato de Rio Bonito. O Município trabalha, com energia, pelo engrandecimento do Estado do Rio e do Brasil.

Considero, portanto, de inteira justiça e da maior conveniência para os interêsses nacionais, a aprovação do Projeto de Lei que virá apressar a execução da Operação Rio Bonito. Federal.

Sala das Sessões, 4 de dezembro de 1957. - Celso Peçanha, Deputado

$$
\text { III - DOCUMENTAÇÃO ANEXA }
$$

1 - OPERAÇÃo RIO BONITO

Sumário:

Desenvolvimento Social e Econômico do Municipio

Dispõe sốbre o desenvolvimento Planificado do Municipio de Rio Bonito, seu enquadramento no sistema geral da "Operação Rio de Janeiro", e dá outras providências.

1 - Objetivos Gerais e Especiais. Instrumentos Legais.

2 - Planificação Municipal. 
3 - Comandos de Produtividade.

4 - Esquema Básico.

5 -- Obras, Empreendimentos e Serviços.

6 - Plano Diretor da Cidade.

7 - Consórcio Intermunicipal e Projetos Locais.

8 - Investimentos. Leis Financeiras.

9 - Financiamentos.

10 - Acôrdos e Empréstimos.

11 - Comissão de Planejamento.

12 - Administração da "Operação Rio Bonito". Rio Bonito".

Fica o Poder Executivo autorizado a organizar e realizar a "Operação

Art. 2. A "Operação Rio Bonito" compreende: I - Plano de Obras, Empreendimentos e Serviços; II - Sistema de Atos Complementares.

\section{Objetivos gerais e especiais - Instrumentos legais}

Art. 3. A "Operação Rio Bonito", conjunto orgânico de projetos, iniciativas e providências, tem os seguintes objetivos principais:

a) transformar o Município em unidade de sustentação e fator do desenvolvimento econômico e social do Estado, mediante investimentos vinculados a projetos geradores de riqueza e de melhoria das condições de vida da população;

b) ampliar e fortalecer a capacidade econômica, financeira e administrativa do Municipio;

c) atrair capitais privados e incentivar a organização de sociedades de economia mista;

d) equacionar e dar solução objetiva aos problemas essenciais do $\mathrm{Mu}$ nicípio, de preferência à base de acôrdos, convênios, consórcios ou contratos multilaterais;

e) reorganizar, dinamizar e modernizar a administração local;

Art. 4. ${ }^{\circ}$ A "Operação Rio Bonito" obedecerá aos princípios fundamentais da autonomia municipal consagrados na Constituição Federal e realizar-se-á segundo técnicas de descentralização racional e municipalização progressiva;

Art. 5. ${ }^{\circ}$ Os objetivos colimados pela "Operação Rio Bonito serão atingidos mediante:

a) a criação de uma Comissão de Planejamento, destinada a organizar o Plano de Desenvolvimento Econômico e Social do Município - "Operação Rio Bonito".

b) a votação do Fundo Especial constituído de recursos cinculados às obras, empreendimentos, serviços e demais iniciativas que a "Operação Rio Bonito" vier a abranger; 
c) o estabelecimento de um sistema multilateral de acôrdos, convênios e contratos, na forma prevista pela presente Lei e Atos que lhes forem subseqüentes ou complementares.

d) a votação de leis especiais que a ampliação, revisão periódica, desdobramentos, adaptações ou modificações da "Operação Rio Bonito", e respectivos projetos exigirem;

e) a expedição de normas ou quaisquer medidas instituidas pelo Sistema de Atos Complementares;

f) a votação de Lei Especial relativa ao sistema financeiro da execução dos planos e projetos da "Operação Rio Bonito";

g) a formulação do Plano de Obras, Empreendimentos e Serviços acompanhado das respectivas Tabelas Discriminativas, estimativas de custo e orçamentos analiticos;

h) o "Plano Diretor da Cidade;

i) o estabelecimento da Comissão Municipal de Desenvolvimento (Administração da "Operação Rio Bonito").

j) a racionalização do aparelhamento governamental e administrativo do Municipio de Rio Bonito, mediante reformas de base e processos de descentraliżação, simplificação e modernização;

k) o enquadramento da "Operação Rio Bonito" no Sistema Geral da "Operação Rio de Janeiro" como uma de suas projeções descentralizadas.

Art. 6. A "Operação Rio Bonito", em sua primeira fase, deverá ser executada em cinco exercícios consecutivos, obedecidos os principios e preceitos fundamentais da presente Lei.

\section{Planificação Municipal}

Art. 7. O Sistema de Atos Complementares a que se refere o item II, do art. $2 .^{\circ}$, compreenderá, principalmente, as seguintes providências: I Lei de Planificação Municipal; II - Comandos de Produtividade.

Art. 8: A Lei de Planificação Municipal estabelecerá as normas juridicas e o regime de funcionamento da «Operação Rio Bonito» tendo em vista dois setores fundamentais: I - Obras, Empreendimentos e Serviços em geral, destinados sobretudo ao desenvolvimento econômico e social do Município; II - O Programa Especial de Melhoramentos Urbanos (Plano Diretor da Cidade).

$\S 1 .^{\circ}$ A Lei de Planificação Municipal prefixará os prazos e discriminará as metas numéricas (quilowats, toneladas, quilômetros, metros cúbicos, etc. ) a serem atingidas, bem assim a localização de cada um dos empreendimentos, obras ou serviços integrantes da "Operação Rio Bonito".

$\S 2 .^{\circ}$ A Lei de Planificação Municipal conterá, entre outros, dispositivos sôbre a reorganização administrativa da Municipalidade; racionalização tributária e codificação em geral. 


\section{Comandos de Produtividade}

Art. 9. Os Comandos de Produtividade instituidos pelo Sistema de Atos Complementares visam acompanhar e fiscalizar a execução dos planos e projetos da "Operação Rio Bonito".

Parágrafo único. Além de outros objetivos que lhes, venham a ser atribuidos deverão os Comandos de Produtividade, em regimem de ampla cooperação com i iniciativa privada, implantar técnicas e métodos racionais de trabalıı, tendo em vista a elevação dos coeficientes de produtividade, economia e eficiência.

Art. 10. O Sistema de Atos Complementares abrangerá propostas, roedidas legislativas, providências ou quaisquer iniciativas, destinadas à plena execução das obras, empreendimentos e serviços em geral, e do Programa Esperial de Melhoramentos Urbanos (Plano Diretor da Cidade), em especial.

\section{Esquema Básico}

Art. 11. A "Operação Rio Bonito", para o efetivo desenvolvimento econômico e social do Municipio, mobilizará recursos tendo em vista resolver os seguintes problemas básicos:

a) industrialização intensiva do Município;

b) eletrificação da sede e dos distritos;

c) desenvolvimento planificado da agricultura; da pecuária e do reflorestamento;

d) conservação de solos e irrigação;

e) reorganização agrária e aproveitamento das áreas improdutivas;

f) ampliação e modernização dos sistemas de transportes e comunicações; população;

g) melhoria das condições de vida e elevação dos niveis culturais da

h) saneamento e urbanismo;

i) exploração industrial do turismo;

j) estudos e levantamentos; pesquisas, investigações cientificas e tecnológicas;

Art. 12. Os objetivos gerais da "Operação Rio Bonito" serão atingidos pela solução gradual dos problemas básicos mencionados no artigo anterior, através das obras, empreendimentos e serviços abaixo discriminados: a) rigoroso entrosamento e perfeita articulação com as iniciativas, projetos e planos de eletrificação, industrialização, espansão agropecuária e outras; b) levantamento da carta aerofotogramétrica e dos mapas pedagógicos do Municipio; c) elaboração e execução coordenada do Programa Especial de Melhoramentos Urbanos de Rio Bonito (Plano Diretor da Cidade), segundo escalas de propriedade e ordens de urgência preestabelecidas. 


\section{Obras, empreendimentos e serviços}

Art. 13. As obras, empreendimentos e serviços a que se refere o artigo anterior constituem a primeira fase da "Operação Rio Bonito", sem prejuizo de outras providências, desde que se enquadrem nas finalidades previstas nos arts. 10,11,12,14 e 15 , e se destinem a complementar, ampliar ou aperfeiçoar o Plano Geral de Desenvolvimento Econômico e Social do Municipio tal como concebido e delineado pela Lei de Planificação Municipal (Obras, Empreendimentos e Serviços Municipais; Programa Especial de Melhoramentos Urbanos - Plano Diretor; Comandos de Produtividade e demais iniciativas do Sistema de Atos Complementares).

\section{Plano Diretor da Cidade}

Art. 14. O Plano Diretor da Cidade, - um dos setores da "Operação Rio Bonito" - constitui um conjunto integrado de melhoramentos urbanos a serem atingidos progressivamente mediante a aplicação concentrada de recursos financeiros e assistência técnica.

Art. 15. As obras, empreendimentos e serviços de primeira urgência e alta prioridade do "Plano Diretor da Cidade", obedecerão ao seguinte escalonamento na solução dos problemas urbanos da sede municipal e distritos: abastecimento dágua; rêdes de esgotos sanitários; energia elétrica; chácaras, hortas e granjas do "cinturão verde", para alimentação do povo; matadouros e frigoríficos; mercadinhos, pontes e estradas sob regime de pedágio; linha interdistritais de transportes; hospitais e casas de saúde; maternidade; escolas técnico-profissionais; colonização em bases cooperativas; bosques e hortos florestais; hotéis; habitações populares.

\section{Consórcio intermunicipal e projeções locais}

Art. 16. A Prefeitura Municipal de Rio Bonito, ouvida a Câmara de Vereadores, tomará tôdas as necessárias providências no sentido de estabelecer um Consórcio Intermunicipal integrando na mesma comunidade de interêsses, os Municípios de Araruama, Cachoeiras de Macacu, Itaboraí Saquarema, Silva Jardim e Maricá.

Art. 17. O Sistema de Atos Complementares (item $\mathrm{H}$, artigo $2 .^{\circ}$ estabelecerá as diretrizes e normas reguladoras do Consórcio Intermunicipal em função dos objetivos específicos e interêsses comuns dos municipios associados.

Art. 18. A "Operação Rio Bonito" far-se-á através de Projeções Locais descentralizadas com denominação especifica diferencial e recursos próprios, abrangendo a totalidade do Municipio

$\S$ i. Ficam desde já instituídas as seguintes Projeções Locais da "Operação Rio Bonito":

I -- Rio Bonito.

II - Imbiara. 
$\S 2 .^{\circ}$ A cada Projeção Local da "Operação Rio Bonito", corresponderá determinado número de projetos, empreendimentos, obras e serviços devidamente coordenados.

\section{Investimentos - Leis financeiras}

Art. 19. Na organização da "Operação Rio Bonito" deverá ser observada, sempre que possível, não só a técnica da municipalização das obras, empreendimentos e serviços, como também prevista a transferência de rendas e encargos da União e do Estado à alçada do Município.

Art. 20. As Cooperativas, Associações Rurais, Industriais e Comerciais, Bancos e Emprêsas privadas idôneas, fica assegurado o direito de colaborar ou participar na execução da "Operação Rio Bonito", segundo cláusulas e condições que forem estabelecidas pelo Sistema de Atos Complementares.

Parágrafo único. A adesão de Cooperativas, Associações Rurais, Industriais e Comerciais, Bancos e Emprêsas privadas à "Operação Rio Bonito" importa na aceitação das bases e diretrizes desta Lei, bem assim dos principios, fundamentos, normas e processos estabelecidos pelo Sistema de Atos Complementares.

Art. 21. A Lei financeira da "Operação Rio Bonito" consignará os recursos necessários à sua execução, tendo por base as seguintes prioridades em relação às obras, empreendimentos e serviços;

a) maior rendabilidade;

b) maior interêsse econômico nacional, regional, municipal;

c) maior interêsse social.

Art. 22. A "Operação Rio Bonito" constituirá um Anexo Especial do Orçamento Geral do Municipio.

Parágrafo único - Ao referido Anexo serão incorporadas as pertentagens de 10,30 e $50 \%$ no caso da participação do Municipio no Sistema Geral das Projeções Regionais e Locais da "Operação Municipio" (Setor Estadual), bem assim apendiculados os Orçamentos das Companhias, Sociedades Mistas ou Emprêsas que forem criadas para a plena realização da "Operaçăo Rio Bonito".

Art. 23. As despesas do custeio e os investimentos selecionados da "Operação Rio Bonito", na parte que constitui responsabilidade direta do Municipio, serão estabelecidos e regulados em tôdas as suas modalidades pela Lei Financeira.

\section{Financiamentos}

Art. 24. O financiamento da "Operação Rio Bonito" será atendido à conta dos seguintes recursos:

a) dotações orçamentárias consignadas no Orçamento Geral do Municipio num montante nunca inferior a 20 por cento da respectiva Proposta Orçamentária Anual; 
b) dotações orçamentárias consignadas no Orçamento Geral do Estado enquanto não se der execução à "Operação Rio de Janeiro". (Projeção Regional e Setor Estadual da "Operação Municipio" de âmbito nacional);

c) produto de operação de crédito em acôrdo especial com o Banco Nacional de Desenvolvimento Econômico, o Banco do Brasil S. A., o Banco Nacional de Crédito Cooperativo, Caixas Econômicas;

d) produto de arrecadação da Contribuição de melhoria, nos têrmos da regulamentação a ser promovida pela Prefeitura, 60 dias após publicação desta Lei;

e) a quota do excesso de arrecadação estadual devida pelo Estado ao Município (Art. 20 da Constituição Federal), enquanto não tiver início o Plano de Desenvolvimento Econômico e Social do Estado do Rio de Janeiro (Operação Rio de Janeiro);

f) percentagem da arrecadação do Impôsto de Indústrias e Profissões, nos têrmos da regulamentação a ser promovida pela Prefeitura, 60 dias após a publicação desta Lei;

g) juros de contas especiais da "Operação Rio Bonito", abertas nos estabelecimentos de crédito já mencionados, para depósito e movimentação dos recursos previstos nesta Lei;

h) revisão e modernização do Sistema Tributário do Municipio, vinculando-se o produto do aumento da arrecadação à "Operação Rio Bonito";

i) taxas, emolumentos, rendimentos e lucros decorrentes da execução das realizações e contratos da "Operação Rio Bonito";

j) a quota especial dos recursos da "Operação Rio de Janeiro" (Plano de Desenvolvimento Econômico e Social dos Municipios fluminenses) destacada para o Setor de Rio Bonito, quota nunca inferior a cinqüenta por cento $(50 \%)$ do total estimado para a "Operação Rio Bonito" nos tếrmos de sua Lei Financeira especifica;

k) dotações consignadas no Orçamento Geral da União que a Bancada Fluminense nas duas Casas do Congresso Nacional conseguir para a "Operação Rio Bonito";

l) vinculação de parte da quota do Impôsto de Renda destinada anualmente ao Município, às obras, e empreendimentos e serviços da "Operação Rio Bonito";

m) rendas eventuais que lhe forem atribuidas; taxas especificas; vinculação de adicionais.

Art. 25. O Poder Executivo Municipal promoverá, desde já, entendimentos e firmará acôrdos ou convênios, com o Estado. Autarquias, entidades paraestatais, sociedades de economia mista, bancos, associações rurais, industriais e comerciais, cooperativas e emprêsas privadas, no sentido de estabelecer esquema de financiamento misto da "Operação Rio Bonito", fixando as condições, natureza e volume da respectiva participação. 
Art. 26. Fica o Poder Executivo autorizado a contrair empréstimos destinados ao custeio e financiamento da "Operação Rio Bonito", planos e projetos que a integram, nos têrmos, condições, volume e prazos fixados pela Lei Financeira.

Art. 27. Para garantia dos empréstimos ou com o fim de reforçar o financiamento do Plano de Obras, Empreendimentos e Serviços, fica o Poder Executivo autorizado a entrar em entendimentos com a Secretaria de Finanças do Estado, no sentido de antecipar a emissão das Apólices ou Obrigaçốes da "Operação Rio Bonito", adquirindo-as o Govêrno Municipal até o montante de $\mathrm{Cr} \$ 75.000 .000,00$ (setenta e cinco milhões de cruzeiros), no qüinqüênio da "Operação Rio Bonito".

Parágrafo único. A amortização e resgate dessa quota especial para a Prefeitura de Rio Bonito serão estabelecidos segundo o Convênio Especial previsto na "Operação Rio de Janeiro", em seus artigos 31,32 e 33.

Art. 28. Fica o Poder Executivo autorizado a celebrar contratos para aquisição, inclusive no exterior, dos materiais e equipamentos indispensáveis à execução da "Operação Rio Bonito", setor municipal da "Operação Rio de Janeiro".

Art 29. Fica o Poder Executivo autorizado a contratar ou organizar, desde já, uma Comissão Técnica destinada a proceder à revisão do Sistema Tributário do Municipio e elaboração do respectivo Código.

Parágrafo único. Fica também o Poder Executivo autorizado a organizar os projetos relativos aos instrumentos legais ou convencionais, mencionados nos artigos 5,6 e 7 .

Art. 30. Fica aberto o crédito especial de $\operatorname{Cr} \$ 200.000,00$ para os trabalhos preliminares de preparo da "Operação Rio Bonito" e inicio das atividades da Comissão de Planejamento referida na letra "a" do artigo 5 ? (Estudos e levantamentos técnico-econômicos).

\section{Comissão de Planejamento}

Art. 31. A Comissão de Planejamento será constituida de 9 (nove) membros nomeados por Decreto do Executivo Municipal em lista encaminhada à Câmara de Vereadores, escolhidos entre técnicos, representantes das classes produtoras e operários.

Parágrafo único. As funções de Membros da Comissão têm caráter civico e seus membros não têm direito a nenhuma remuneração, considerados relevantes os seus serviços.

\section{Administração da "Operação Rio Bonito"}

Art. 32. Noventa dias (90) após o encerramento dos trabalhos da Comissão de Planejamento (Art. 5, "a"; art. 31 e parágrafo único) entrará em imediato funcionamento a Administração da "Operação Rio Bonito". 
Art. 33. Fica instituida a Administração da "Operação Rio Bonito" para executar e coordenar as obras, empreendimentos e serviços que a integram. (Comissão Municipal de Desenvolvimento).

$\S 10$ O Prefeito Municipal será o Administrador-Geral da "Operação Rio Bonito", auxiliado por 3 (três) Assessôres Técnicos.

$\S 2 .^{\circ}$ A estrutura e funcionamento da "Operação Rio Bonito", no que se refere à sua Administração, serão estabelecidos pelo Sistema de Atos Complementares e pelas disposições contidas no Regulamento na presente Lei.

Art. 34. O Prefeito Municipal, a Câmara Municipal, os Sindicatos de Classes, as Cooperativas, Associações Rurais, Recreativas e Esportivas do Municipio, assim como as pessoas gradas de Rio Bonito, se dirigirão à Assembléia Legislativa Estadual, ao Governador do Estado e Partidos Politicos, encarecendo a alta conveniência da imediata votação e sanção da "Operação Rio de Janeiro" (Plano de Desenvolvimento Econômico e Social do Estado do Rio de Janeiro), cujos objetivos, recursos e providências condicionam a perfeita realização de um de seus setores e projeções descentralizadas - a "Operação Rio Bonito".

Art. 35. O Poder Executivo expedirá o Regulamento da presente Lei 60 (sessenta) dias após a sua publicação.

Art. 36. Esta Lei entrará em vigor na data de sua publicação, revogadas as disposições em contrário.

\section{2 - OPERAÇÃo RIO BONITO}

\section{Uma projeção local da "Operação Municipio"}

Mensagem Fluminense aos Prefeitos e Vereadores do Brasil.

A “Operação Rio Bonito" estabelece as bases e diretrizes de um sistema de administração planificada, que tem como um de seus objetivos primordiais "promover e acelerar o desenvolvimento econômico-social do $\mathrm{Mu}$ nicipio".

Essa meta fundamental é uma resultante da pesquisa e avaliação do potencial econômico de Rio Bonito, e deverá ser realizada em função do bemestar de seus 35.000 habitantes e sua plena integração no progresso geral do Estado do Rio.

Ela representa, portanto, a demonstração mais recente do novo estilo de Municipalismo que surgiu em São Lourenço, em maio de 1954, com a "Operação Municipio", suas Projeções Regionais e locais.

Sendo pelas suas caracteristicas técnicas uma dessas Projeções Locais descentralizadas, a "Operação Rio Bonito" vem, realmente, aperfeiçoar e fortalecer as tendências revolucionárias de Govêrno e Administração Municipal, consubstanciadas no Sistema Geral da "Operação Municipio". 
Dai o motivo pelo qual, mais cedo do que se presume, deverá a "Operação Rio Bonito" ser objeto de rigorosa análise e amplos debates em muitas Prefeituras e Câmaras do Pais, Assembléias Legislativas, Círculos Universitários e Governamentais, da União e dos Estados, em virtude da originalidade, sensatez e objetividade das soluções que ela preconiza para os problemas fundamentais da Cumuna.

Em poucas palavras, a "Operação Rio Bonito" significa uma concepção arrojada e dinâmica de administração municipal; o estabelecimento de um regime de planificação; a participação do Município - em escala sem precedentes - no Orçamento Geral e nos Orçamentos Cambiais da União; melhor entrosamento com a Administração Estadual e um tratamento mais satisfatório dos problemas locais pelos órgãos ou autoridades do Estado; a implantação de um Consórcio Intermunicipal que reunirá os Municipios vizinhos em uma mesma comunidade de interêsses, multiplicando-lhes as possibilidades de trabalho e rendimento do esforrço conjunto; um programa cientientificamente planejado de obras, empreendimentos e serviços geradores de riquezas; o estabelecimento de um Plano Diretor da Cidade que deverá incorporar as mais avançadas concepções urbanísticas; investimentos, empréstimos e financiamentos de vulto, acôrdos. convênios e contratos multilaterais; racionalização administrativa; intensa colaboração popular - em resumo - tôdas as atividades, iniciativas, providências e medidas legislativas diversas que configuram e definem uma Projeção Local da "Operação Municipio".

O traço característico mais importante da "Operação Rio Bonito", reside na sua plena e total exeqüibilidade técnica, econômica e financeira esta conclusão resulta da análise de sua estrutura, delineamentos técnicos. setores e projetos que a integram e, sobretudo, da estimativa dos recursos orçamentários e extra-orçamentários destinados ao seu financiamento.

As exigências do desenvolvimento nacional e regional - quer financeiras, administrativas ou simplesmente técnicas - estão impondo enérgicas providências, simultâneamente com uma tomada de posição em face das reivindicaçöes generalizadas, cujo atendimento, no todo ou em parte, constitui para a União e para os Estados motivo de graves apreensões. Êsse é o caso, entre outros, da Campanha Municipalista, que infelizmente vem assumindo, dia a dia, as estranhas proporções de um vasto movimento organizado contra a União: - o alvo predileto de queixas e reclamações de tôda ordem. A "Operação Rio Bonito" reage contra essa deformação das tendências e deturpação das finalidades da nobre Campanha. A "Operação Rio Bonito" repele êsse desvio de orientação, nitidamente demagógico, reconhece e prociama a alta prioridade dos problemas e interêsses do Brasil.

As reivindicações municipalistas que mais diretamente repercutem sôbre a estrutura econômica da Federação são as diversas propostas de uma nova discriminação de rendas. E, a êste respeito, reconhecem os prefeitos, vereadores, técnicos e politicos que se faz mister uma decisão urgente no tocante às sérias divergências que, indiscutivelmente, colocam em campo antagônico os interêsses da União, dos Estados e Municipios. E' o velho conflito que $n s$ teóricos de um federalismo superado fingem ignorar - quando entram 
em choque as aspirações de cada órbita, reclamando uma maior participação no produto das rendas arrecadadas. No caso da rediscriminação de rendas, por exemplo, o antagonismo dos interêsses é flagrante, procurando a União, os Estados e os Municípios dividir entre si o produto da arrecadação arrecadada ans contribuintes, na base de critérios empiricos e superficiais que perpetuam as injustiças, já conhecidas, que os municipalistas não se cansam de apregoar. Os Estados, por sua vez, não estão satisfeitos, e, em sua tota lidade, se apresentam deficitários, reclamando, com tôda razão, um quinhão maior das rendas públicas. Até o presente momento, os Estados estão atrasados ne pagamento das quotas constitucionais de 30 por cento do excesse da arrecadação estadual (Art. 20 da Carta Magna). A situação financeira dos Estados é de tal ordem que nenhum dêles se encontra, no momento. 2m condições de dar integral cumprimento às suas responsabilidades para com as respectivas Comunas, no que se refere a êsse dispositivo constitucional. Nenhuma órbita da Federação se considera satisfeita com a sua parte na partilha tributária. Mas, enquanto ninguém cuida dos Estados, encontra-se em plena atividade um movimento reivindicatório de proporções inéditas, no sentido de serem atendidas as Comunas às expensas da União. Os impostos básicos de renda e consumo - esteio da segurança orçamentária da União - são os mais visados.

A "Operação Rio Bonito" foi concebida de tal forma que, embora tenha como uma de suas finalidades básicas o fortalecimento financeiro do Município, ela poderá atingir êsse alvo preferencial sem qualquer sacrifício para a União ou para o Estado do Rio. A fórmula extremamente simples consiste na utilização racional de tôdas as potencialidades da cooperação intergovernamental e interadministrativa, no recurso aos financiamentos governamentais e privados, na racionalização tributária e numa efetiva participação popular.

Quanto à união, apesar de seus encargos e responsabilidades serem os mais pesados, ninguém se lembra de defendê-la; é a "galinha dos ovos de ouro". Nos circulos municipalistas mais acentuadamente demagógicos, tornou-se um hábito "elegante" deblaterar contra a União; nenhum orador ou "lider" obterá sucesso perante as massas semi-alfabetizadas - com as notórias e honrosas exceções do conhecimento geral - se antes de qualquer exórdio nâo vergastar o Govêrno Federal. E' uma verdadeira mania essa, malhar de rijo a União e os seus respectivos órgãos, embora para ela todos se dirijam e dela tudo esperem, inclusive os milagres do equilibrio financeiro c do desenvolvimento econômico. Também a êste respeito a orientação exclusivamente técnica da "Operação Rio Bonito", apesar dos riscos da impopularidade, reafirma o imperativo da cooperação com o Govêrno Federal e com os grandes empreendimentos industriais do Estado Brasileiro: - a Petrobrás, a Companhia Siderúrgica Nacional, a Fábrica Nacional de Motores, a Companhia Nacional de Álcalis, a Companhia Hidrelétrica do São Francisco, a Companhia Vale do Rio Doce, o Banco Nacional do Desenvolvimento Econômico e tantas outras instituições importantes pelas quais a União é responsável.

Examinadas com serenidade as questões em aprêço - desenvolvimento nacional e regional, por um lado; fortalecimento econômico-social dos mu- 
nicípios, por outro - temos que convir que existem profundas divergências e conflitcs de interêsses a serem resolvidos em função exclusiva dos imperativos de sobrevivência da Federação, dos princípios da colaboração reciproca e vantagens mútuas. O Brasil reclama soluções ténicas, científicas e, ao mesmo tempo, justas. Isto significa a realização de estudos profundos $e$ definitivos, ainda não efetuados. A redistribuição de rendas é um caso tipico sôbre o qual, ao invés dêsses indispensáveis estudos, existem apenas pronunciamentos exaltados e uma acentuada exacerbação reivindicatória. Em virtude do velho círculo vicioso em que vivemos, sacrificam-se às áreas municipais para atribuir-se recursos aos "problemas de bases", às chamadas "questóes maiores"; sacrificam-se, por outro lado, as referidas "questões maiores" porque as menores, - inclusive a municipal, - vivem a requerer cada vez mais recursos, fundamentalmente destinados a fins federais. Os programas regionais de valorização econômica (Vale do São Francisco, Poligono das Sêcas, por exemplo), vêm sendo sacrificados justamente porque substancia parcela dos recursos constitucionais atribuidos a tais programas que estão sendo empregados sem um adequado planejamento quando deveriam ser concentrados nos empreendimentos básicos a que se destinam por fôrça dos próprios dispositivos constitucionais. De boa-fé ninguém poderá negar o muito que a União vem tentando, em favor das áreas municipais.

O Orçamento Federal vem sendo sacrificado em seus fins específicos justamente porque boa parte da receita federal destinada a propósitos federais, vem sendo desviada para obras e serviços municipais e sem nenhuma garantia para os interessados, dada a intermiténcia da votação dos recursos, visto que vinculados a objetivos eleitorais, na maioria dos casos: Além disso os Estados pobres e desprestigiados como o Piaui, o Maranhão, - o Nordeste, em geral - são postergados na distribuição das verbas e esquecidos, - totalmente olvidados - nos esquemas de investimentos federais, em benefício dos Estados mais poderosos política e econômicamente. O velho provérbio "os rios correm sempre para o mar", tem um perfeito simile na permanente e volumosa canalização de recursos, investimentos, créditos, iniciativas diversas para as zonas de maior densidade econômica, as zonas de concentração do Poder. "Mutatis Mutandis", a situação dos Municípios ainda é pior; em cêrca de 2.500 Comunas, há aproximadamente 80 que conseguem ᄏlguma coisa: - são as grandes Prefeituras que dispõem de relativo prestigio político. As demais, - isto é, a quase totalidade dos Municípios - que se dêem por satsfeitas com os dez por cento da quota do Impôsto de Renda E o Municipio de Rio Bonito é um dos que também se encontram nessa situação penosa.

E no entanto, - essa é uma das contradições e paradoxos da civilizaऽão brasileira: - a tendência do legislador é pràticamente incoercivel ric sentido de destinar, cada vez mais, maiores recursos para serviços e obras de caráter municipal. Mas essa distribuição é ilógica e antinacional: os auxilios, contribuições e subvenções diversas que obstruem o Orçamento $\mathrm{Fe}$ ¿'eral, bem como os acôrdos e convênios realizados pelos Ministérios com os Municípios não obedecem a nenhum plano de conjunto; é o empirismo total; é a dissipação maciça; é a multiplicação das pequenas "vantagens" aparen. 
tes; é a proliferaçâo de iniciativas insignificantes. Isoladamente nenhum problema básico se resolve, mas, no conjunto alguns bilhões de cruzeiros são jogados fora sem proveito para o País, e, o que é pior, sem vantagens apreciáveis para as populações do Interior.

Porque então não organizar em benefício dos Municipios, um Plano de conjunto, garantido por receita federal especifica, inclusive por recursos ex. tra-orçamentários e capitais privados? Dizem que os Municipios não que rem - e fazem muito bem - "andar de chapéu na mão". Mas, como conseguirão isso - se não impuserem ao Govêrno Federal um programa geral de valorızação das áreas municipais, que, obrigatòriamente, por lei, seja executado mediante convênios com as Prefeituras ou Consórcios Municipais, programa êste no qual estejam consubstanciadas as suas principais reivindicações? E, isso, com a garantia legal - através de legislação adequada, cie que os recursos serão entregues e aplicados durante cinco anos consecutivos em regime de descentralização integral, tal como propõe a "Operação Municipio".

Os líderes municipalistas estão redondamente equivocados quando pensam que com a Reforma Constitucional, pela qual se batem, tendo em vista uma nova rediscriminação de rendas - estarão resolvidos todos os problemas municipais. E' preciso não ter a noção exata da realidade tributária e financeira - em têrmos de quantitativos e números exatos - para acreditar em semelhante ilusão. Na hipótese em que porventura sejam vitoriosas as propostas até agora divulgadas, os Municipios passarão a receber um pouco mais nos primeiros anos; os que atualmente recebem 700 mil cruzeiros, talvez consigam obter um milhão e quatrocentos. As dificuldades se agravarão, todavia; desde já, a desvalorização da moeda, o ritmo emissionista, o aumento dos salários e de mão de obra, do preço das utilidades e materiais de construção, dos equipamentos, etc., todos êsses fatôres negativos de uma conjuntura inflacionária já se incumbiram de anular, por antecedência, as supostas vantagens. $\mathrm{E}^{\prime}$ mesmo espantoso que êsses lideres 'se empenhem de tal forma em busca de uma solução empírica, que na prática vai se revelar como um paliativo, uma simples ajuda. Nos têrmos em que foi apresentada, a discriminação de rendas é a panacéia, a grande ilusão do Municipalismo. Uma verdadeira discriminação de rendas ainda não foi estudada com a serenidade que se faz mister, com espirito de justiça e rigor cientifico, a fim de que não se perpetue no Brasil o circulo visioso já referido, as agitações reivindicatórias permanentes, a proliferação de demagogos e tartufos de tôda a espécie que, a pretexto de servirem aos Municipios, são verdadeiros sanguessugas de sua economia, vorazes intermediários e traficantes de influência política.

Há os que se insurgem contra o contrôle técnico e a orientação dos projetos por parte da União, assim como se, de boa-fé, estivessem convencidos de que as municipalidades brasileiras dispensam assistência técnica. Mas de assistência todos nós, no mundo inteiro, estamos necessitados. Negá-la às municipalidades do País seria crime, mesmo porque é essa assistência uma das reivindicações fundamentais das mesmas. 


\section{3 - "OPERATION RIO RONITO"}

I - Developpement Social et Economique du Municipe.

II - Message aux Prefets et aux Conseillers Municipaux du Bresil. canti.

Traduction du Prof. Alexis Maurin, Wilson Kleber et Araújo CavalAssociação Brasileira de Municipios — Rio de Janeiro - 1957.

\section{“OPERATION RIO BONITO”}

\section{Developpement Social et Economique du Municipe}

Sommaire

L "Operation Rio Bonito" réglement le développement du Municipe de Rio Bonito, précise les modalités de son encadrement dans le sistème général de 1'"Opération Rio de Janeiro" et envisage diverses autres mesures.

1 - Objectifs généraux et objectifs spéciaux. Instruments Légaux.

2 - Planification Municipale.

3 - Commandos de Productivité.

4 - Schéma Fondamental.

5 - Oeuvres, Entreprises et Services.

6 - Plan Directeur de la Ville.

7 - Consortium Intermunicipal et Projections Locales.

8 - Investissements. Lois Financières.

9 - Financement.

10 - Accords et Emprunts.

11 - Commission de Planification.

12 - Administration de 1'"Opération Rio Bonito".

Art. $10^{\circ}$ Le Pouvoir Exécutif est chage de l'organisation et de la réalisation de 1 "'Opération Rio Bonito".

Art. 2. $\quad$ L'“'Opérition Rio Bonito comprend: I - Le Plan des Oeuvres, des Entreprises et des Services. II - Le Système des Actes complémentaires.

\section{Objectifs generaux et objectifs speciaux Instruments legaux}

Art. 3. ${ }^{\circ}$ Les objectifs principaux de 1'“Opération Rio Bonito", ensemble organique de projets, d'initiatives et de mesures, cont les suivants:

a) transformer le Municipe pour en faire une unité et un facteur di1 développement économique et social de l'Etat, au moyen d'investissements affectés à des projets susceptibles d'engendrer des richesses et de conduire à une amélioration des conditions de vie de la population.

b) amplifier et renforcer les possibilités économiques, financières et administratives du Municipe. 
c) attirer les capitaux privés et stimuler l'organisation de sociétés d'économie mixte.

d) poser et résoudre de façon objective les problèmes essentiels du Municipe en utilisant de préférence des accords, des conventions, des consortiums ou des contrats multilatéraux. locale.

e) réorganiser, renforcer l'efficacité et moderniser l'administration

Art. 49 "L'Opération Rio Bonito" obéira aux principes fondamentaux de l'autonomie municipale consacrés dans la Constituion Fédérale, et se réalisera suivant des techniques de décentralisation rationnelle et de municipalisation progressive.

Art. 5. Les objectifs visés par 1"' Opération Rio Bonito" seront atteints à l'aide des mesures suivantes:

a) création d'une Commission de Planification destinée à établir le plan de Déveppement Economique et Social du Municipe - (Opération Rio Bonito);

b) vote d'un Fonds Spécial constitué par des ressources affectées à des oeuvres, des entreprises, des services et éventuellement, à d'autres initiatives de 1'“'Opération Rio Bonito";

c) établissement d'un ssystème multilatéral d'accords, de conventions et de contrats dans la forme prévue par la présente Loi et les Actes Subséquents et Complémentaires.

d) vote des lois spéciales exigées par l'ampliation, la révision périodique, les développements, les adaptations ou les modifications de 1"“Opération Rio Bonito" et des projets s'y rapportant;

e) exécution des normes ou des mesures instituées par le Système des Actes Complémentaires;

f) vote de la Loi Spéciale relative au système financier adopté pour l'exécution des plan et des projets de 1'“Opération Rio Bonito";

g) établissement d'un Plan des Oeuvres, des Entreprises et des SerServices accompagné d'un Tableau analytique de leurs Budgets respectifs;

h) Plan Directeur de la Ville;

i) Création de la Comission Municipale de Développement et d'Administration de 1'“'Opération Rio Bonito";

j) Rationalisation de l'appareil gouvernemental et administratif du Municipe de Rio Bonito, au Moyen de réformes de base et de procédés de décentralisation, de simplification et de coordination;

k) Encadrement de 1"'Opération Rio Bonito" dans le système Général de l'"Opération Rio de Janeiro", comme l'une de ses projections décentralisées.

Art. 6. L'“'Opération Rio Bonito" devra, au cours de sa première phase, être exécutée en cinq exercices consécutifs obéissant aux principes et aux préceptes fondamentaux de la présente Loi. 


\section{Planification Municipale}

Art. 7. Le Système des Actes Complémentaires auquel se réfère l'item II de l'art. 2, comprendra, principalement, les mesures suivantes:

I - Loi de Planification Municipale; II - Création de Commandos de Productivité.

Art. 8. ${ }^{\circ}$ La Loi de Planification Municipale établira les normes juridiques et le régime de fonctionament de l'“Opération Rio Bonito" en considérant les deux secteurs fondamentaux suivants: I - Oeuvres, Entreprises te Services, destinés avant tout au développement économique et social du Municipe; II - Programme Spécial d'Améliorations Urbaines (Plan Directeur de dla Ville).

§ 1 - La Loi de Planification Municipale fixera les délais, elle établira, en termes quantitatifs (kilowatts, tonnes, kilomètres, mètres cubes, etc....) les objectifs à atttindre, ainsi que les tâches respectives des Oeuvres, des Entreprises et des Services participant à 1'“Opéracion Rio Bonito".

$\$ 2$ - La Loi de Planification Municipale contiendra, entre autres, des dispositions sur la réorganisation administrative du Municipe, la rationalisation des impôts et la codification en général.

\section{Commandos de Productive}

Art. 9. Les Commandos de Produvtivité institués par le Système des Actes Complémentaires son chargés d'accompagner et de contrôler l'exécution des plans et des projets de 1"“ Opération Rio Bonito".

Paragraphe unique. En plus des autres objectif, les Commandos de Productivité devront, dans un régime d'ample coopération avec l'initiative privée, implanter des tecniques et des méthodes rationnelles de travail visant à l'élévation des coefficients de productivité, d'économia et d'efficacité.

Art. 10. Le Système des Actes Complémentaires s'étendra aux propositions, aux mesures législatives, et à toutes les iniciatives destinées à la pleine exécution du Programme des oeuvres, des entreprises et des services en général, et du Programme Spécial d'Améliorations Urbaines, en particulier.

\section{Schema fondamental}

Art. 11. Pour rendre effectif le développement économique et social du Municipe, l' "Opération Rio Bonito" mobilisera les ressources, dans le but de sésoudre les problémes fonpamentaux suivants:

a) industrialisation intensive du Municipe;

b) électrification de la Capitale et des Districts; ment;

c) développement planifié de l'agriculture, de l'élevage et du reboise- 
d) conservation des sols et irrigation;

e) réorganisation agraire et utilisation des surfaces improductives;

f) amplification et modernisation des moyens de transport et de communication;

g) amélioration des conditions de vie et élévation des niveaux culturels de la population;

h) assainissement et urbanisme;

i) exploitation industrielle $\mathrm{du}$ tourisme;

j) études et relevés de plans, recherches, investigations scientiriques et technologiques.

Art. 12. Les objectifs généraux de 1'“'Opération Rio Bonito" seront atteints par la solution graduele des problèmes fondamentaux cités dans l'article précédent, au moyen des oeuvres, des entreprises et des services indiqués plus loin. Leur réalisation nécessite: a) une entente rigoureuse et une parfaite articulation entre les initiatives, les projets et les plans d'électrification, d'industrialisation, d'expansion de l'agriculture et de l'élevage, etc.... b) le revelé de la carte aérophotométrique et des cartes dédologiques du Munique; c) l'élaboration et l'exécution coordonnée du Programme Spécial d'Améliorations Urbaines de Rio Bonito (Plan Directeur de la Ville), sujvant des règles de priorité et un ordre d'urgente pré-etablis.

\section{Oeuvres, entreprises et Services}

Art. 13. Les oeuvres, entreprises et services auxquels se réfère l'article précédent constituinte la première phase de 1"'Opération Rio Branco", sans préjudice d'autres mesures, à condition pu'elles se placent dans le cadre des objectifs prévus aux articles $10,11,12,14$ et 15 , et qu'elles soient destinées à compléter, à amplifier ou à perfectionner le Plan général de Développement Economique et Social du Municipe (Oeuvres, Entreprises et Services Municipaux; Programma Spécial d'Amériorations Urbaines; Plan Directeur; Commandos de Productivité et autres initiatives du Système des Actes Complémentaires).

\section{Plan Directeur de la Ville}

Art. 14. Le Plan Directeur de la Ville - une des composantes de l'"Opération Rio Bonito" - constitue un ensemple d'améliorations urbaines à réaliser progressivement, grâce à une utilisation efficace des ressources financières et le l'assistance technique.

Art. 15. Les Oeuvres et Services de première urgence et de grande priorité du Plan Directeur de la Ville rechercheront dans d'ordre suivant la solution des problèmes urbains de la capitale municipale et des districts: adduction d'eau; réseau d'égouts sanitaires; énergie électrique, fermes, jar- 
dins et métairies de la "ceinture verte" poul l'alimentation de la population; abattoirs et frigoriques; marchés; ponts et routes avec péage; moyens de communication entre les districts; hôpitaux et maison de santé; maternités; écoles techniques et professionnelles; coopératives; bois et parcs forestiers; rôtels; habitations populaires.

\section{Consortium Intermunicipal et projetions locales}

Art. 16. La Préfecture Municipale de Rio Bonito, après avoir entendu le Conseil Municipal, prendra les mesures nécessaires à la création d'un Consortium Intermunicipal unissant dans une même communauté d'intérêts les Municipes de Araruama, Cachoeiras de Macabú, Itaborai Saquarema, Silva Jardim, Maricá et Rio Bonito.

Art. 17. Le Système des Actes Complémentaires (item h, article 2) établira les directives et les normes réglementant le Consortium Intermunicipal en fonction des objectifs spécifiques et des intérêts communs des Municipes associés.

Art. 18. L'"Opération Rio Bonito" qui embrase la totalité du Municipe se fera au moyen de Projections Locales décentralisées avec pour chacune une dénomination spécifique et des resources propres.

$\S 1$ - Sont déjà instituées les Projections Locales suivantes de l'“'Opération Rio Bonito":

I - Rio Bonito.

II - Imbiara.

§. 2 - A chaque Projection Locale de 1'“'Opération Rio Bonito" correspondra un nombre déterminé de projets, d'entreprises, d'oeuvres et de services dûment coordonnés.

\section{Investissements - Lois financieres}

Art. 19. Dans l'organisation de l'"Opération Rio Bonito", la technique de municipalisation des ceuvres, des entreprises et des services devra être appliquée à tous les cae le permettant; de même, devra etre prévu le transw fert des revenus et des charges de l'Union et de l'Etat du ressort du Municipe.

Art. 20. Aux Coopératives, aux Associations Rurals, Industrielles et Commerciales, aux Banques et Sociétés Privées compétentes, sera assuré droit de collaborer ou de participer à l'“Opération Rio Bonito", conformément aux clauses et conditions établies par le Système des Actes Complémentaires.

Paragraphe unique. La participation de Coopératives, d'Associations Rurales, Industrielles et Commerciales, de Banques et d'Entreprises Privées à l'"Opération Rio Bonito" est soumise à l'acceptation les bases et des directives de lá présente Loi, ainsi que, à celle des principes, des dègles, des normes et des procédés établis par le Système des Actes Complémentaires. 
Art. 21. La Loi Financière de 1'“Opération Rio Bonito" consignera des ressources nécessaires à son exécution, en observant les régles de priorité suivantes relatives aux oeuvres, aux entreprises et aux services:

a) plus grande rentabilité;

b) plus grand intérêt économique national, régional, municipal;

c) plus grand intérêt social.

Art. 22. L'“Opération Rio Bonito" constituera une annexe spéciale du Budget Général du Municipe.

Paragrafe unique. A l'annexe citée seront incorporés les pourcentages de 10, 30 et $50 \%$ dans le cas de participation du Municipe au Système Général des Projection Régionales et Locales de 1'“Opération Municipe" (Secteur de l'Etat), ainsi que, en appendice, les Budgets des Compagnies, des Sociétés Mixtes ou des Entreprises crées pour la pleine réalisation de 1'“'Opération Rio Bonito".

Art. 23. Toutes les modalités des dépenses et des investissements sélectionnés de 1'“Opération Rio Bonito", en ce qui concerne la partie placée sous la responsabilité directe de la Municipalité, seront établies et reglementées par la Loi Financière.

\section{Financement}

Art. 24. Le financement de 1"'Opération Rio Bonito" será assuré à 16aide des ressources suivantes;

a) dotations budgétaires consignées dans le Budget Général du Municipe, d'un montant jamais inférieur à $20 \%$ de la ôroposition Budgétaire Annuelle;

b) dotations budgétaires consignées dans le Budget Général de l'Etat tant que 1'“'Opération Rio de Janeiro" n'a pas reçu d'exécution - (L'“'Opé. ration Rio de Janeiro" est une Projection Régionale dans le secteur de l'Etal de 1" Opération Municipe" envisagée sur le plao national);

c) produit de l'“'Oopération de crédit, en accord spécial avec la Ban. que du Brésil S. A., la Banque Nationale de Crédit Coopératif, les Caises Economiques; la Banque Nationale de Développement Economique;

d) produit du recouvrement de la Contribution dé Amélioration suivant les termes de la réglementation à promulger par la préfacture 60 jours oprés la publication de cette Loi;

e) la quotité de l'Etat dû par "Etat au Municipe (Art. 20 de la Cons. de l'Etat de Rio de Janeiro (Opération Rio de Janeiro) n'a pas reçu un détituin Fédérale), tant que le Plan de Développement Economique et Social but d'application;

f) pourcentage de l'impôt sur les Industries et sur les Professions suivant les termes de le réglementation à promulger par la Préfecture 60 jours aprés la publication de cette Loi; 
g) intérêts des comptes spéciaux de l'"Opération Rio Bonito" ouverts dans les établissements de crédit déjá cités pour le dépôt et le mouvement des ressources prévues dans cette Loi;

h) révision et modernisation du Système des Contributions du Municipe, le produit de l'augmentation du recourvrement étant affecté à l'"Opération Rio Bonito";

i) taxes, emoluments, revenus et bénéfices décourlant de l'exécution cies contrats, etc. des réalisations de 1"“Opération Rio Bonito";

j) la part spéciale de l'“'Odération Rio de Janeiro" (Plan de Développemente Economique et Social des Municipes de l'Etat de rio de Janeiro) affectée au Secteur de Rio Bonito, par jamais inférieure à cinquante pour cent $(50 \%)$ du total prévu pour 1'“'Opération Rio Bonito", suivant les termes de sa Loi Financière spécifique;

k dotations consignées dans le Budget Général de l'Union à obtenir pour 1'."Opération Rio Bonito" par les représentants de l'Etat de Rio ou Congres National;

l) affectation d'une partie de la cote de l'impôt sur le Revenu destinée annuellement au Municipe, aux oeuvres, aux enterprises et aux services de 1'“'Opération Rio Bonito";

m) revenus éventueis; taxes particuliéres e taxes additionnelles.

Art. 25. Le Pouvoir Exécutif Municipal doir provoquer, des à présent, des ententes, et signe des accords ou des conventions avec l'Etat, les Autarchies, les Sociétés d'Economie Mixte, les Banques, les Associations Rurales, Industrielles et Commerciales, les Coopératives et les Enterrises privées, pour établir un schéma de financement mixte de 1"'Opération Rio Bonito", fixant les conditions, la nature et l'importance de leurs participations respectives.

Art. 26. Le Pouvoir Exécutif est autorisé à contracter des emprunts destinés au financement de 1'“Opération Rio Bonito" des plans et des projets qui en font partie, suivant les termes, les conditions, le volume et les délais par la Loi Financière.

Art. 27. Pour garantir les emprunts et afin de renforcer le financement du Plan des Oeuvres, des Enterprises et des Services, le Pouvoir Exécutif est autorisé à conclure des ententes avec le Secrétariat des Finances de l'Etat, dans le but de faciliter l'émission des "Apolices et des Obligations de l'"Opération Rio Bonito", le Gouvernement les acquelant jusqu'a concurrence de 75.000.000,00 de cruzeiros (soixante quinze milions de cruzeiros).

Paragraphe unique. L'amortissement et le rachat de cette cote spéciale par la Préfecture de Rio Bonito seront effectués suivant la Convention Spéciale prévue dans 1'"Opération Rio Bonito", dans les articles 31, 32 et 33.

Art. 28. Le Pouvoir Exétif est autorisé à signer des contrats pour lacquisition, même à l'extérieur, du matériel et de l'équipament indispensables à l'éxcution de 1'“Opération Rio Bonito", secteur municipal de 1"“Opération Rio de Janeiro". 
Art. 29. Le Pouvoir Exécutf est autorisé à contracter ou à constituer, dès à présent, une Commission Technique destinée à procéder à la révision du Système des Contributions du Municipe et à l'élaboration du Code s'y rapportant.

Paragraphe unique - Le Pouvoir Exécutif etc autorisé, égallment, à rassembler et organiser les projetc relatifs au instruments légaux ou conventionnels mentionnés dans les articles 6,7 et 8 .

Art. 30. Est ouvert un crédit spécial de 200.000,00 Crs. (deux cent mille cruzeiros) destiné aux travaux préliminaires de preparation de 1'“Opération Rio Bonito" et aux premières activités de la Commission de Planification citée au paragraphe a de l'article 5 (Etudes et relevés techniques et économiques).

\section{Comission de Planificacion}

Art. 31. La Comission de Planification sera composée de 9 (neuf) membres nommés par Décret de l'Exécutif Municipal, sur une list envoyée au Conseil Municipal, ces membres étant choisis parmi des techniciens et des représentants des claises de producteurs et d'oucriers.

Paragraphe unique. Les fonctions de Membre de la Comission ont un caractère civique et ses membres a'ont droit à aucune rémunération, leurs services étant considérés comme honorifiques.

\section{Administration de l"Opération Rio Bonito"}

Art. 32. Quatre vingt dix jours (90) aprés la clôture des travaux de la Commission de Planification (Article 5, a, Art. 31 e $\S$ unique) l'Administration Rio Bonito", entrera en fonction.

Art. 33. L'Administration de 1"'Opération Rio Bonito" est instituée pour exécuter et coordonner les Oeuvres, les Enterprises et les Services qui en font partie (Commission Municipale de Développement).

Parágraphe 1. Le Préfet Municipal será l'Administrateur Général de 1"Opération Rio Bonito" avec pour auxiliaires trois (3) assesseurs techniques.

Paragraphe 2. En ce qui concerne son Administration, la structure et le fonctionnement de 1'"Opération Rio Bonito" seront établis par le Système des Actes Complémentaires et par les dispositions contenues dans le Réglemente de la présente Loi.

Art. 34. Le Préfet Municipal, la Chambre Municipal, les Syndicats des classes, les Coopératives, les Associations Rurales, Récréatives et Sportives du Municipe, ainsi que les personnalités de Rio Bonito, s'adresseront à l'Assemblée Legislative de l'Etat, au Governeur de l'Etat et aux Partis Politiques, pour sonligner l'intérét d'un vote immédiat et de l'Opération Rio de Janeiro (Plan de Développement Economique et Social de l'Etat de Rio 
de Janeiro), dont les objectifs, les ressouces et les mesures conditionnentla parfaite realisation d'une de ses Projections decentralisées: - 1'“Opération Rio Bonito".

Art. 35. Le Pouvoir Exécutif expédiera le Réglement de la présente Loi, soixante jours $(60)$ après sa publication.

Art. 36. Cette Loi entrera em vigor à la date de sa publication, toutes cispositions contraires étant abrogées. - Araújo Cavalcanti et Wilson Kleber.

\section{Note du traducteur:}

Au point de vue administratif, le Brésil comprend ving Stats, cinq Territoires et le District Fédéral de Rio de Janeiro. Le Municipe est une division territoriale et administrative des Estats; le nombre des Municipes de chaque Etat est variable: Le Municipe de Rio Bonito se situe dans l'Etat de Rio de Janeiro. - Alexis Maurin.

\section{"OPERATION RIO BONITO"}

\section{Une projection locale de $l^{\prime \prime \prime}$ Opération Municipe"}

Message aux prejets et aux Conseillers Municipaux du Bresil

L'“'Opération Rio Bonito" établit les bases et les lignes principales d'un nouveau système d'Administration planifiée, dont l'un des objectifs principaux este de "provoquer et d'accélerer le développement économique et social du Municipe".

Cette tâche fondamentale qui nécessite l'étude et l'évaluation du potentiel économique de Rio Bonito elle devre être réalisée en fonction du bien-être des 35.000 habitantes de Municipe, et de sa parfaite intégration dans o cadre du progrés général de l'Etat de Rio.

Cette opération représent donc la plus récente démonstration d'un nouveau style de Municipalisme apparu à São Lourenço, en Mai 1954, avec 1"Opération Municipe", et ses Projections Régionales et Locales.

Etant par ses caractéristiques une de ces Qrojections Locales décentralisées, 1" Opération Rio Bonito" vient, effectivament, perfectionner et renforcer les tendances révolutionnaires de Gouvernement et d'Administration Municipale contenues dans le système général de l'“Opération Municipe".

Pour ce motif, et en vertu de l'originalité, de la sagesse et de l'objectivité des solutions qu'elle préconise pour les problèmes fondamentaux de la Comune, 1 "Opération Rio Bonito" devra, dans un avenir plus proche qu'en ne le présume généralement, être l'objet d'une analyse rigoureuse et d'amples débats dans beaucoup de Préfectures et de Chambre du Pays, dans les Assemblées Législatives, les Cercles Universitaires et Gouvernementaux de i'Union et des Etats. 
En rérumé, 1'“'Opération Rio Bonito" représente une conception audacieuse et dynamique de l'Administration Municipale; elle implique l'établissement d'un régime de planification; la participation du Municipe - à une échelle sans précédent - au Budget Général et au dudget des Changes de IUnion; une meilleure entente avec l'Administration de l'Etat et, pour les organismes et les autorités de l'tat une façon plus satisfaisante de traiter les problèmes locaux; la création d'un Consortium Intermunicipal qui réunira les Municipalités voisines dans uns même communauté d'intérêts, multipliant ainsi leur potentiel de travail et le rendement de l'effort accompli en commun; un programme scientifiquement établi, pour oeuvres, les entreprises et les services susceptibles d'engendrer des richesses; l'établissement d'un Plan Directeur de la Ville qui groupera les conceptions d'urbanisation les plus avancées; elle implique aussi des accords, des conventions et des contrats multilatéraux, une rationalisation administrative et une active colleboration populaire; autrement dit 1'“Opération Rio Bonito" réprésente toutes les activités, les iniciatives, les mesures législatives qui définissent et caractérisent une Projection Locale de 1" Opération Municipe".

Le trait le plus important de 1'“Opération Rio Bonito" réside dans le fait que, techniquement, économiquement et financièrement, elle est entièrement réalisable: cette conclusion résulte de l'analyse de sa structure, de ses caractéristiques techiniques, des secteurs et des projets qui en font partie, et surtout de l'estimation des ressources budgétaires et extra-budgétaires destinées à son financement.

Les exigences du développement national et régional - exigences financières, administratives ou même simplesment tecniques - necessitent d'énergiques mesures et, simultanément une prise de position en face de devendications généralisées que constituent pour l'Union e pour les Etats un motif de grave appréhension. C'est le cas, entre autres, de la Campagne Municipaliste qui, malheureusement, prend chaque jour davantage les étranges proportions d'un vaste mouvement organisé contre l'Union, cible préférée des plaintes et des revendications de toutes sortes. L'"Opération Rio Bonito" réagit contre cette déformation des tendances et cette dénaturation des buts de la Campagne L'“'Opération Rio Bonito" repousse changement d'orientation, nettement démagogique; elle reconnait et proclame la haute priorité des problémes et des intérêts de l'Union qui, de toute evidence, sont les problémes et les intérêts du Brésil.

Les revendications des partisans de la Municipalisation qui se répercutent le plus diretement sur la structure économique de la Fédération se traduisent par des propositions relatives à une nouvelle distribution des revenus. A ce sujet, les Préfets, les Conseillers Municipaux, les techniciens, les hommes politiques reconnaisent la nécessité d'une lécision urgente réglant les sérieuses divergences qui opposent de façon indiscutable les intérêts de l'Union, des Etats et des Municipes. C'est le vieux conflit que les théoriciens d'un fédéralisme depasse feignent d'ignorer lorsque entrent en opposition les aspirations de ces diverses Institutions, chacune d'elles réclamant uns participation plus grande au produit des revenus. Dans le cas d'une nouvelle discrimination des rentes par exemple l'antagonisme des intérêts 
est flagrant, l'Union, les Etats et les Municipes cherchant à diviser entre eux le produit de la contribution arranchée aux contribuables en se basant sur des critères empiriques et superficiels qui perpétuaent les injustices bien connues que les Municipalités ne cessent de dénoncer. Les Etats de leur côté ne sont pas satisfaits, et tous se presentent comme déficitaires, réclamant à juste titre, une part plus grande des revenus publics. Jusqu'à mainteâ nant les Etats sont en retard pour le paiement des quotités constitutionnelles de $30 \%$ de l'excédent de lá Contribution de l'Etat (Art. 20 da "Carta Magna"). $\mathrm{La}$ situation financière des Etats est telle, actuellement, qu'aucun d'eux n'est en mesure de remplir ses obrigations envers les Municipes, en ce qui concerne cette disposition constitutionnelle. Aucun élément de la Féderation ne se considère comme satisfait de la part de l'impôt qui lui est attribuée. Mais álors que persone ne s'inquiète des Etats, il existe un mouvement revendicatif de proportions inédites tendant à faire bénéficier les Municipes des dépenses de l'Union. Les impôts de base: impôt sur le revenu et impôt de consommation, sur lesquels se fonde la sécurité budgétaire de l'Union, soni les plus visés.

Bien que l'une de ses fins principales soit le renforcement financier du Municipe, l'"Opération Rio Bonito" a été conçue de façon à pouvoir atteindre cet objectif sans aucun sacrifice simple, consiste à utiliser rationnellement toutes les forces de la coopération inter-governamentale et inter-administrative dans le recours aux financements par le Gouvernement et les capitaux privés, dans la rationalisation des contributions et dans la recherche dune parcipation populaire effective.

Quant à l'Union, bien ses charges et ses responsabilités soient les plus lourdes, personne ne songe à la défendre; c'est "la poule aux oeufs d'or". Dans les cercles municipalistes où la démagogie est poussée à l'extrême, déblatérer contre l'Union est devenu une habitude élégante; à part quelques exceptions connues, aucun orateur, aucun leader n'obtiendra du succés devant les masses semi-ignorantes si son exorde n'est précédé d'une attaque contre le Gouvernement Fédéral. C'est une véritable manie de critiquer violemment l'Union et ses organismes; cependant tous se torunent vers elle tt en attedent tout, y compris le miracle de l'équilibre financier et du développement économique. A ce sujet également l'orientation exclusivement tecnique de I'"Opération Rio Bonito", malgre les risques d'impopularité, réaffirme l'impérie use necessité d'une collaboration avec le Gouvernement Fédéral et avec les grandes entreprises industrielles de l'Etat Brésilien: la $\mathrm{Pe}$ trobras, la Compagnie Sidérurgique Nationale, la Fabrique Nationale de Moteur, la Compagnie Nationale des Alcalis, la Compagnie Hydro-électrique de São-Francisco, la Compagnie "Vale do Rio Doce", la Banque Nationale de Développement Economique et tant d'autres institutions importantes dont l'Etat est responsable.

Aprés un examen impartial des problémes dontil est question - développement national et régional d'une part, renforcement économique et social des Municipes d'autre part-nous devons convenir qu'il faut résoudre en fonction de l'impératif de survie de la Fédération et des principes de collaboration réciproque et de sontien mutuel. Le Brésil réclame des solutions 
techniques, scientifiques, et en même temps justes. Ceci implique la réalisation d'études profondes et définitives non encore effectuées. La redistribution des revenus est un cas typique sus lequel, au leiu de ces études indispensables, existent seulement des opinions exaltées et des revendications exacerbés. Nous continuons à vivre dans un cercle vicieux: on sacrifie les questions municipales pour atribuir les ressources aux "problémes de base", a ce que l'on appelle des "questions supérieures", mais d'un autre côte on sacrifie ces mêmes "questions supérieures" parce que les problémes d'importance moindre - en particuler le problème municipal - nécessitent chaque jour davantage de ressouces normalement destinées par leur nature à des questions fédérales. Les programmes régionaux de valorisation économique (Bale do São-Francisco, Polygone de la Sécheresse, par exemple) ont été sacrifiés parce qu'une part substancielle des ressources attribuées à de tels programmes a été employe sans une planification convenable, au lieu d'être concentrée dans les entreprises essentielles ainsi que the prévoient les dispositions constitutionnelles. Persone de pourse, de bonne foi, nier l'ffort tenté par l'Union en faveur du secteur municipal.

Le Budgest Fédéral a été sacrifié dans scs fins spésifiques, precisément parce qu'une bonne partie de la recette fédéral (destinée à des questions fédérales) a été détournée vers des oeuvres et des services municipaux, sans alicune garantie pour les interessés étant donné l'intermittence du vote des ressources et sa subordination à des objectifs électoraux dans la majorité des cas. En plus de cela, les Etats pauvres et de peu d'importante tels que le Piaui, le Maranhão, le Nort-Est en général - sont laissés en arrière lors de la répartition des crédits et totalment oubliés dans les plans des investissements fédéraux, au bénéfice des Etats économiquement et politiquement plus puissants. Le vieux proverbe "les ruisseaux coulent toujours la mer "est parfaitement illustré par la canalisation permanente des dessources, des investissements, des crédits, des initiatives diverses vers les zones de plus grande clensité économique, des zones de concentration du pouvoir. "Mutatis $\mathrm{Mu}$ tandis" la situation des Municipes est encore pire; sur 2.500 Municipes 80 environ obtiennent quelquer chose: ce sont les grandes Préfectures qui jouissent d'un certain prestige politique. Les autres - c'est à dire la presque totalité des Municipes - se tiennent pour satisfait avec dix pour cent de la cote de l'Impôt sur le revenu. Le Municipe de Rio Bonito est un de ceux qui se trouvent dans cette pénible situation.

Cependant, et ceci est une des coutradictions et un des paradoxes de la civilisation brésilienne, la tendance du législateur est de consacrer sans cesse de plus grandes ressources à des serviçes et à des ouvres à caractère municipal. Mais cette distribution est illogique et antinationale; les seccours, les contributions, les subventions divers qui grevent le Budget Fédéral, ainsi. que les accordes et les conventions passés entre les Ministères et les Municipalités n'obéissent à aucun plan d'ensemble; c'est l'empirisme total; c'est la dissipation massive des capitaux, c'est la multiplication des petits "profits" apparents; c'est la prolifération des initiatives insignifientes. Pris isolément aucun problème fondamental n'est résolu; néanmoins l'ensemble des dépen- 
ses se traduit par quelques miliards de cruzeiros gaspillés sans aucun profit pour le Pays, et ce qui est pire, sans aucun avantage appreciable pour les populations de l'intérieur.

Pourquoi alors ne pas organiser au bénéfice des Municipes un plan d'ensemble garanti par une recette fédérale spéciale, et même par des ressources extra-budgétaires et des capitaux privés? Les Municipalités disent, avec raison, du'elles se refusent à mendier. Mais comment parviendront-elles à un resultat si elles n'imposent pas au Gouvernement Fédéral un programme général de valorisation du Municipe dont une foi redrait obrigatoire l'exécution à l'aide de conventions avec la Préfecture et les Consortiunms Municipaux, programme dans lequel seraient concrétisées leurs principales revendications? Ceci avec la garantie légale, fournie par une législation convenablement adaptée, que les ressources seront distribuées et utilisées durant cinq années consécutives en régime de décentralisation intégrale, ainsi que le préconise 1'"Opération Municipe".

Les leaders municipalistes se trompent prossièrement lorsqu'ils pensen! que, grâce à la Constitutionnelle pour laquele ils luttent en vue d'obtenir une nouvelle distribution des revenus, tous les problèmes seront résolus sur le plan municipal. Il faut ne pas avoir la notion exacte de la réalité en matiére de contributions et de finances pour se bercer d'une semblable illusion. Dans Thypothèse, Où par aventure, ces propositions seraient victorieuses, les Municipes recevront un peu plus au cours des premières années; celles qui resoivent actuellement 700.000 cruzeiros en obtiendront peut-être un million quatre cent mille. Les difficultés s'aggraveront néanmoins; dès à présent la dévalorisation des salaires et de la main d'ouvre, du prix des matériaux de construction, de l'équipement, etc.... tous ces facteurs négatifs d'une conjoncture inflationniste, se sont chargés d'annuler à l'avance les avantages supposés. Il est même surprenant que ces leaders s'emploient de telle façon à rechercher une solution empirique que, dans la pratique, va se révéler un simple paliatif. Suivant les termes dans desquels elle a été discutée, la discrimination des revenus est la panacée, la grande ilusion du Municipalisme. Une véritable discrimination des revenus n'a pas encore été étudiée avec le sérieux nécessaire, avec un escrit de justice, avec une riguer scientifique, de façon à ce que cessent d'exister pour le Brésil le cercle vicieux précédemment cité toutes ces agitations revendicatrices permanentes et cette prolifèration de especes qui, sous prétexte de servir les démagogues et de tartufes de toutes Municipes, sont de véritables sangsues de leur économie, de voraces intermediaires et dos trafiquants de l'influence politique.

Certains s'insurgent contre le contrôle tecnique et une orientation des projets de la part de l'Union comme s'ils étaient sincèrement convaincus que les Municipes Brésiliens pouvaient se passer d'assistance técnique. Mais. l'assistance technique est nécessaire à tous, dans le monde entier. Nier cette nécessité pour les Municipes du Brésil serait une faute grave d'autant plus que cette assistance technique est une de leurs revendications principales. Araújo Cavalcanti. - Wilson Kleber. 